\title{
Doğuştan çarpık ayak epidemiyolojisi
}

\section{Congenital clubfoot epidemiology}

\author{
Rahmi Can Akgün, Orçun Şahin
}

Başkent Üniversitesi Hastanesi, Ortopedi ve Travmatoloji Anabilim Dalı, Ankara

\begin{abstract}
Çarpık ayak, ayağın konjenital bir deformitesi olarak günümüzde en sık karşılaşılan pediatrik doğumsal anomalidir. Çarpık ayağın neden kaynaklandığı ve olası risk faktörleri konusunda literatürde çok farklı çalışmalar bulunmaktadır. Buna karşın, literatürde kesin kabul görmüş bir fikir birliği henüz oluşmamıştır. Daha kaliteli çalışmaların yapılabilmesi için, yenidoğan bir bebek çarpık ayak tanısı aldığında, uygun kodlama, yeterli bilgi kaydı ve bilgilerin ulusal bir veri ağına aktarılması gibi daha ileri işlemlerin uygulanması gerekmektedir. Böylelikle, yenidoğan çocukların çarpık ayak açısından daha sağlıklı değerlendirilebilir hale gelmesi ve olguların doğru şekilde tespit edilerek kayıt altına alınması mümkün olacaktır. Literatürde genel kabul gören görüş, çarpık ayak olgularının her yeni bin doğumda bir görüldüğü ve yıllık 150.000 'den fazla yeni olgunun tespit edildiği şeklindedir. Çarpık ayak risk faktörleri incelendiğinde ise, embriyolojik ve mekanik faktörler ile genetik ve çevresel faktörlerin araştırıldığı, ek olarak maternal risk faktörleri ve akraba evliliği gibi sorunların da incelendiği görülmektedir.
\end{abstract}

Anahtar sözcülkler: çarpık ayak; epidemiyoloji; risk faktörleri
As a congenital malformation, clubfoot is one of the most common foot abnormality of the childhood. There are various studies in the literature with regard to the etiology and possible risk factors of the clubfoot. Nevertheless, there is still an ongoing debate about the actual cause of this abnormality. In oder to have more qualified studies, all newborns with clubfoot should be registered in a national database with relevant codes of diagnosis and demographic information. By this way, all newborns with clubfoot can be accurately followed and treated and the cases are recorded properly. The general consensus in the literature is that clubfoot is seen in one in every thousand live births, and each year 150 thousand new cases are diagnosed with this abnormality. The risk factors for the clubfoot that have been already analyzed in the literature include embriological and mechanical factors, and genetic and environmental factors. Additionally, maternal risk factors and problems related to consanguinity have also been evaluated in the literature.

Key words: clubfoot; epidemiology; risk factors

\section{Çarpık Ayak Epiyemiyolojisi Neden Önemli?}

Doğumsal pes ekinovarus (PEV) veya daha yaygın kullanılan ismi ile çarpık ayak, ayağın konjenital bir deformitesi olarak günümüzde en sık karşılaşılan pediatrik doğumsal anomalidir. ${ }^{[1]}$ Uygun bir şekilde tedavi edilmediğinde ciddi problemlere neden olan çarpık ayağın klinik olarak bu denli önemli olmasının nedeni, uygun tedavi edilmeyen olgularda görülen yürüme bozukluğu ve yaşam boyu aksamadır. Bu nedenden dolayl; bu doğumsal anomalinin etiyolojisi, risk faktörleri, ilişkili diğer hastalıkları, tipleri, tanı ve tedavi yöntemleri, oldukça önemli ve üzerinde araștırılması gereken konulardır. Çarpık ayak, görülme sıklığı ve klinik önemi ile birlikte, sosyal, psikolojik ve ekonomik sorunlara neden olan ve tıbbı tedavi harcamalarına ciddi yük getiren önemli bir hastalık olarak kabul edilmektedir. Son birkaç yılda meydana gelen cesaret verici gelişmeler ile birlikte, çarpık ayağın sıklığı, olası etiyolojik nedenleri ve risk faktörlerine daha çok ilgi duyulmaya başlanmış ve bu konu üzerindeki insidans çalışmaları ve çarpık ayak epidemiyolojisinin daha iyi anlaşııması için yapılan risk faktör analizleri, özellikle son on yılda hız kazanmıştır. ${ }^{[2]}$

Günümüzde birçok farklı teori üretilmesine ve bu konuda hakkında oldukça farklı kaynaklardan birçok epidemiyolojik çalışmalar bulunmasına rağmen, halen bu anomalinin gerçek epidemiyolojik faktörleri ortaya çıkartılamamıştır. Çarpık ayak epidemiyolojisinin tam

- İletişim adresi: Doç. Dr. Rahmi Can Akgün, Başkent Üniversitesi Hastanesi, Ortopedi ve Travmatoloji Anabilim Dalı, Mareşal Fevzi Çakmak Cad., 10. Sok., No: 45, Bahçelievler, Ankara Tel: 0312 - 2126868 e-posta: rahmicana@yahoo.com

- Geliș tarihi: 25 Mayıs 2015 Kabul tarihi: 25 Mayıs 2015 
olarak anlaşılması ile birlikte, bu anomaliye neden olan etiyolojik faktör(ler) gün ışığına çıkartılacak, olası risk faktörleri belirlenerek erken dönemde müdahale olanağı bulunacak ve gerek tanı ve sınıflama, gerekse de tedavi yöntemlerinin başarı oranı arttırılabilecektir.

\section{Epidemiyolojik Çalışmaların Temel Sorunu}

Temel olarak, doğumların hastanelerde gerçekleştiği ve kayıt altına alındığı modern sağlık sistemlerinde, konjenital çarpık ayak deformitesi ile dünyaya gelen bir yenidoğanın sağlık çalışanları tarafından fark edilmesi ve ileri tetkik/tedavi amacı ile ortopedi kliniğine yönlendirilerek bu deformitenin kayıt altına alınması, normal bir süreç olarak kabul edilir. Bu sayede, o sağlık sistemi içerisindeki gerçek çarpık ayak insidansı belirlenerek, olası risk faktörleri sağlıklı bir şekilde araştırılabilir. Böyle bir sistemde, pratik olarak, bir hastaya yanlışııkla çarpık ayak tanısı konması veya çarpık ayağı olan bir hastanın sağlıklı kabul edilmesi, çok düşük bir olasılıktır. ${ }^{[3]}$ Bu bakış açısı ile, yenidoğan bir bebek çarpık ayak tanısı aldığında; uygun kodlama, yeterli bilgi kaydı ve bilgilerin ulusal bir veri ağına aktarılması gibi daha ileri işlemler gerekmektedir. Bütün bu kayıt ve işlemlere rağmen, halen sistemde yanlışlık olabilmektedir. Insidansın belirlenmesinde, kayıt sistemine girmeyen doğumlar ve çarpık ayak olguları her zaman olabilmektedir. Buna karşın, bazı yenidoğanlara yanlışlıkla çarpık ayak tanısı konularak, insidans göreceli olarak fazla da bulunabilmektedir. Bu sorunların ortadan kalkarak gerçek insidansın belirlenebilmesi ve buna bağı olarak da epidemiyolojik çalışmaların daha sağııklı hale getirilebilmesi için, sağlık sistemlerindeki kayıt işlemlerinin daha verimli hale getirilmesi, ulusal bilgi ağlarının oluşturulması ve belki de en önemlisi, sağlık çalışanlarının bilgilendirilmesi ile farkındalığın arttırılması gerekmektedir. Böylelikle, yenidoğan çocukların çarpık ayak açısından daha sağlıklı değerlendirilebilir hale gelmesi ve olguların doğru bir şekilde tespit edilerek kayıt altına alınması amaçlanmaktadır.

\section{EPIDEMIYOLOJiK ARAŞTIRMALAR VE INSIDANS BILGISi}

Literatüre baktığımızda, çarpık ayak ile ilgili insidans, etiyoloji, tanı ve güncel tedavi yaklaşımlarını içeren, pek çok farklı kaynaktan değişik çalışmalar olduğunu görmekteyiz. ${ }^{[1,2,4]}$ Medline ve Pubmed taramalarında ise, yayın sayısı bakımından 70 ve 80 'li yıllarda hemen hemen sabit giden yayın sayısının, özellikle 1990 yılından itibaren belirgin bir artış gösterdiği ve bu artış eğiliminin günümüzde de halen devam ettiği görülmektedir (Şekil 1).

Bu yayın sayısındaki artış eğiliminin nedenlerine bakıldığında, bunların en önemlisinin özellikle idiyopatik tipteki çarpık ayak deformitesinin insidans ve epidemiyolojik risk faktör analizleri olduğu görülmektedir. Özellikle son on yıl içerisinde, çarpık ayağın risk faktörleri, bölgesel ve mevsimsel insidans değişikleri, etnik kökensel bir farklılık olup olmadığı, genetik ve çevresel faktörler ile eşlik eden rahatsızıklarla ilgili olarak çok

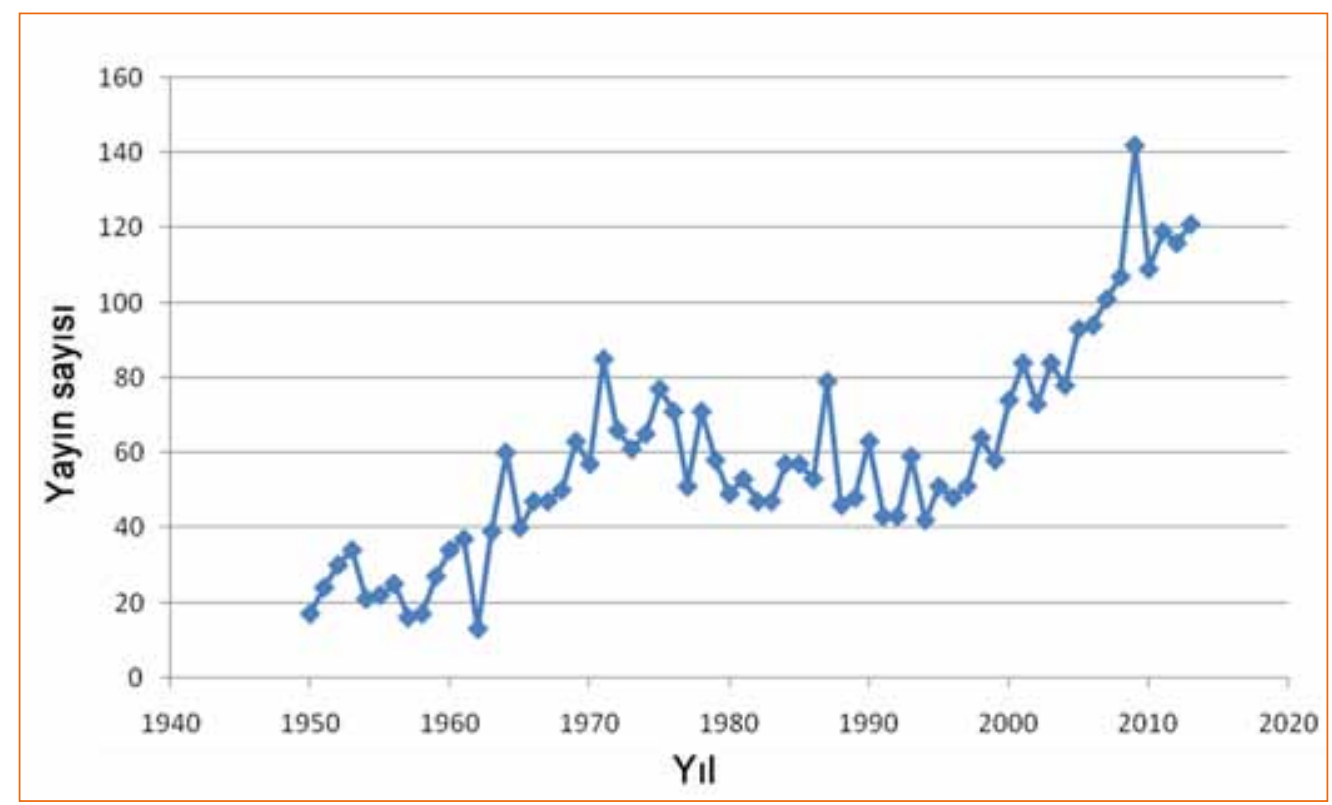

Şekil 1. Yayın Sayısı / Yıl çizelgesi. 
sayıda farklı epidemiyolojik çalışma olduğu görülmektedir. ${ }^{[2,5-7]}$ Bu epidemiyolojik çalışmalara bakıldığında, en sık rastlanan çarpık ayak tipinin idiyopatik çarpık ayak olduğu görülmektedir. Daha az oranda ise, miyelomeningosel veya artrogripozis gibi başka medikal sendromlara eşlik eden çarpık ayak olguları literatürde bildirilmiştir.

Literatürde genel kabul gören görüş, çarpık ayak olgularının her yeni bin doğumda bir görüldüğü ve yıllık 150.000 'den fazla yeni olgunun tespit edildiği şeklindedir. $^{[2]}$ Bu genel kabul gören insidans verisi, etnik köken, coğrafi konum ve ülkeler arasında farklılık gösterebilmektedir. Olguların \%80'i ise gelişmekte olan ülkelerde görülmektedir. Polinezya toplumunda bin doğumda 6,8 oranında görülen çarpık ayak insidansı, beyaz ırkta 1,12 , hispaniklerde 0,76 ve Çinlilerde ise 0,39 oranında bildirilmiştir. ${ }^{[2]}$ Etnik kökenden bağımsız olarak, ilk çocuklarda daha sık ve erkeklerde iki kat daha fazla görülüğü bilinmektedir ve olguların yarısında çarpık ayak bilateraldir. Tek taraflı olgularda ise sağ tarafa daha fazla etkilenmektedir. Correa ve arkadaşlarının, 2007 yılında yaptıkları 30 yıllık bir takip araştırmasında, nöral tüp defekti olmayan hastalardaki çarpık ayak görülme sıklığının giderek düştüğü de bildirilmiştir. ${ }^{[3]}$

\section{ETIYOLOJiK ÇALIŞMALAR VE RISK FAKTÖR ANALIZLERi}

Çarpık ayağın kesin etiyolojik faktörleri halen tam olarak bilinmemektedir. Bugüne kadar ortaya konan nedensel faktörler, çalışmaların farklı popülasyonlarda ve farklı kayıt sistemlerinde yapılmalarından dolayı tartışmalıdır. Bu faktörler Tablo 1'de özetlenmiştir.

\section{Embriyolojik/Maternal Faktörler}

Çarpık ayak oluşumundaki faktörler incelendiğinde, ilk olarak, anne karnındaki sıkıştırıcı kurvetler ve mekanik faktörlerin bir rol oynayabileceği düşünülmüştür.

Tablo 1. Çarpık ayak için olası etiyolojik faktörler

\begin{tabular}{ll}
\hline Sinir lezyonları & Bölgesel/etnik farklılıklar \\
\hline Musküler anormallikler & Mevsimsel farklııklar \\
Vasküler defektler & Anne yaşı \\
Nöromusküler hastalıklar & Anne eğitim düzeyi \\
Bölgesel büyüme bozuklukları & Parite \\
İntrauterin bası & Akraba evliliği \\
Erken amniyosentez & Sigara kullanım öyküsü \\
Genetik ve çevresel faktörler & Anne diyabeti
\end{tabular}

Bu nedenle uzun yıllar boyunca literatürde, breech pozisyonlu doğum, oligohidroaminoz, çoklu gebelik gibi faktörlerin bu deformitenin oluşumundaki temel faktör olup olmadığı tartışılmıştır. ${ }^{[7]}$ ỉlerleyen yıllarda, embriyonik gelişme basamaklarının daha iyi anlaşılması ile beraber, bu teoriden giderek uzaklaşılmıştır. Gebeliğin 9. haftasında ekstremite tomurcuklarının oluşması ve vertikal eksende dizilim gösteren bu tomurcuklanmanın, gebeliğin 14. haftasında mediyale dönerek, normal ayak diziliminin gerçekleşmesi olası mekaniksel faktörlerin rol oynayabileceğini gösterse de, ilerleyen yıllarda yapılan araştırmalar bu teorinin şu an için çok da geçerli olmadığını göstermektedir. ${ }^{[7]}$ Bu çalışmalardan ikisi, literatürde önemli bir rol oynamaktadır. Illk olarak, çarpık ayaklı çocuklarda, posterior ve mediyal bacak kas gruplarındaki nörolojik bir gelişimsel soruna işaret eden Tip 1 liflerinde uyumsuzluk tespit edilmiştir. ${ }^{[6]}$ Daha sonraki yıllarda, Diestz ve arkadaşları, ayak parmak fleksörleri ve tibialis posterior kas grubun tendon kılıfındaki hücrelerde hipoplazi tespit ederek, çarpık ayak gelişimini bu soruna bağlamışlardır. ${ }^{[8]}$

Çarpık ayak etiyolojisinde, embriyolojik çalışmalara ek olarak, maternal risk faktörleri de araştırılmıştır. Çok farklı çalışmalar olmasına rağmen, genel olarak; maternal yaş, parite, anne eğitim düzeyi, çalışma durumu gibi faktörlerin çarpık ayak etiyolojisinde kesin rol oynadığı kanıtlanmış değildir.

\section{Genetik/Çevresel Faktörler}

Anne karnındaki embriyolojik ve mekanik faktörlerin yanı sıra genetik ve çevresel faktörlerinde çarpık ayak gelişiminde rol oynayabileceği düşünülerek, literatürde farklı çalışmalar yayınlanmıştır. Literatürde ek olarak, akraba evliliğinin de, özellikle idiyopatik çarpık ayak gelişiminde bir risk faktörü olabileceği bildirilmiştir. Şahin ve arkadaşlarının yapmış oldukları bir hastane tabanlı olgu-kontrol çalışmasında, 1. derece akrabalığın, çarpık ayak gelişiminde dört kattan daha fazla risk doğurduğu tespit edilmiştir. Ek olarak, ileri gestasyonel yaş, erkek cinsiyet ve annenin çalışan biri olmasının da çarpık ayak için risk faktörü olduğu, aynı çalışmada bildirilmiştir. ${ }^{[9]}$

İkizler üzerinde yapılan çalışmalarda ise, çarpık ayak etiyolojisinin genetik bir tabanı olup olmadığı anlaşılmaya çalışıııı̧tır. Genetik olarak, monozigotik ikizlerin tümüyle, dizigotik ikizlerin ise $\% 50$ oranında aynı genleri taşıdığı ve tüm ikizlerin aynı antenatal ortamı paylaştığı bilinmektedir. Bu nedenle, olası genetik faktörlerin konjenital hastalıklar üzerindeki etkilerini belirlemek mümkündür. Her iki bireyinde etkilendiği monozigotik ikizlerde, dizigotik ikizler ile kıyaslandığında daha fazla çarpık ayak deformitesi görüldüğü literatürde bildirilmiştir. Bu durum, hastalık için genetik 
etiyolojiyi işaret etmektedir. Bu bulgu, Engel ve arkadaşları tarafından doğrulanmıştır. Engel ve arkadaşlarının yapmış olduğu bir çalışmada, eğer monozigotik ikizlerden biri çarpık ayak deformitesi ile doğmuşsa diğer ikizde çarpık ayak görülme sıklığı üçte bir olarak bildirilmiştir. ${ }^{[5]} \mathrm{Bu}$ durum, deformitenin altında kısmi genetik etiyoloji olduğunu güçlü bir şekilde göstermektedir. İdiyopatik çarpık ayak deformitesi ile doğan bir bireyin birinci derece akrabalarında çarpık ayak deformitesi olma riski, normal popülasyona göre daha fazladır. Daha önceki çalışmalarda, idiyopatik çarpık ayak deformitesi olan bir çocuğun kardeşinde \%2-4 oranında çarpık ayak görülme riski olduğu da bildirilmiştir. ${ }^{[5]}$

Son yıllardaki teknolojik gelişmelere paralel olarak, moleküler genetik çalışmalar da hız kazanmış ve çarpık ayak epidemiyolojisinde rol oynayan spesifik predispozan genler üzerindeki araştırmalar önem kazanmıştır. Çalışmalarda, tek başına bir gen veya muhtemel poligenik nedenler araştırılmış ve olası çevresel faktörler ile çarpık ayak epidemiyolojisi aydınlatılmaya çalışılmıştır. Bu çalışmalarda, kızlarda hastalığın kalıtılması için erkeklere göre daha fazla genetik yüke ihtiyaç olduğu belirlenmiştir. Wang ve arkadaşlarının yaptığı bir başka çalışmada ise, çarpık ayak için iskelet kası proteinini (Fhl1) direkt olarak regüle eden Hoxd13 geni ile ilişki tespit edilmiştir. ${ }^{[10]}$ Ek olarak, erken amniyosentez $(E A=11-12+6$ gestasyonel haftalar) uygulanmasının, mid-trimester $(\mathrm{MA}=15-16+6)$ amniyosentez uygulamasına veya hiç amniyosentez uygulanmamasına göre 10 kat daha fazla çarpık ayak riskinde artışla ilişkili olduğu gösterilmiştir. Kadınlarda geniş çapta yapılan bu ileriye dönük randomize çaIışma sonucunda, amniyon sıvısındaki geçici kaçağın çarpık ayak deformitesi oluşmasına katkıda bulunabileceği sonucuna varılmıştır. ${ }^{[11]}$

Çarpık ayak etiyolojisinde tartışılan çevresel faktörlerin başında ise; mevsimsel/coğrafik değişiklikler, sosyokültürel ve ekonomik faktörler ile sigara kullanımı gibi birtakım farklı alanlar gelmektedir. Mevsimsel olarak enterokok enfeksiyonlarının daha sık görüldüğü aylarda doğan çocuklarda, çarpık ayak görülme sıklığının artış gösterdiği literatürde bildirilmiştir. Aynı şekilde, sigara kullanımının da çarpık ayak için bir risk faktörü oluşturduğu, yine literatürdeki çalışmalarda belirtilmiştir.[1,2,12]

\section{KAYNAKLAR}

1. Parker SE, Mai CT, Strickland MJ, Olney RS, Rickard R, Marengo L, Wang Y, Hashmi SS, Meyer RE; National Birth Defects Prevention Network. Multistate study of the epidemiology of clubfoot. Birth Defects Res A Clin Mol Teratol 2009;85(11):897-904. CrossRef

2. Werler MM, Yazdy MM, Mitchell AA, Meyer RE, Druschel CM, Anderka M, Kasser JR, Mahan ST. Descriptive epidemiology of idiopathic clubfoot. Am J Med Genet A 2013;161A(7):156978. CrossRef

3. Correa A, Cragan JD, Kucik JE, Alverson CJ, Gilboa SM, Balakrishnan R, Strickland MJ, Duke CW, O'Leary LA, RiehleColarusso T, Siffel C, Gambrell D, Thompson D, Atkinson M, Chitra J. Reporting birth defects surveillance data 1968-2003. Birth Defects Res A Clin Mol Teratol 2007;79(2):65-186.

4. Palma M, Cook T, Segura J, Pecho A, Morcuende JA. Descriptive epidemiology of clubfoot in Peru: a clinic-based study. lowa Orthop J 2013;33:167-71.

5. Engell V, Damborg F, Andersen M, Kyvik KO, Thomsen K. Club foot: a twin study. J Bone Joint Surg Br 2006;88(3):374-6.

6. Handelsman JE, Badalamente MA. Neuromuscular studies in clubfoot. J Pediatr Orthop 1981;1(1):23-32.

7. Kawashima T, Uhthoff HK. Development of the foot in prenatal life in relation to idiopathic club foot. J Pediatr Orthop 1990;10(2):232-7.

8. Dietz FR, Ponseti IV, Buckwalter JA. Morphometric study of clubfoot tendon sheaths. J Pediatr Orthop 1983;3(3):311-8.

9. Sahin O, Yildirim C, Akgun RC, Haberal B, Yazici AC, Tuncay IC. Consanguineous marriage and increased risk of idiopathic congenital talipes equinovarus: a case-control study in a rural area. J Pediatr Orthop 2013;33(3):333-8. CrossRef

10. Wang LL, Fu WN, Li-Ling J, Li ZG, Li LY, Sun KL. HOXD13 may play a role in idiopathic congenital clubfoot by regulating the expression of FHL1. Cytogenet Genome Res 2008;121(34):189-95. CrossRef

11. Farrell SA, Summers AM, Dallaire L, Singer J, Johnson JA, Wilson RD. Club foot, an adverse outcome of early amniocentesis: disruption or deformation? CEMAT. Canadian Early and Mid-Trimester Amniocentesis Trial. J Med Genet 1999;36(11):843-6.

12. Byron-Scott $R$, Sharpe $P$, Hasler $C$, Cundy $P$, Hirte $C$, Chan $A$, Scott $\mathrm{H}$, Baghurst $\mathrm{P}$, Haan E. A South Australian populationbased study of congenital talipes equinovarus. Paediatr Perinat Epidemiol 2005;19(3):227-37. 